\title{
Synaptic and Nuclear Localization of Brain-Enriched Guanylate Kinase-Associated Protein
}

\author{
Ikuko Yao, Junko lida, Wataru Nishimura, and Yutaka Hata \\ Department of Medical Biochemistry, Graduate School of Medicine, Tokyo Medical and Dental University, Bunkyo-ku, \\ Tokyo 113-8519, Japan
}

\begin{abstract}
Brain-enriched guanylate kinase-associated protein (BEGAIN) interacts with postsynaptic density (PSD)-95/synapseassociated protein (SAP) 90. In immunohistochemistry and immunocytochemistry, BEGAIN was detected in nuclei and at synapses in neurons. Nuclear localization was also confirmed through subcellular fractionation. BEGAIN was localized exclusively in nuclei when expressed in epithelial cells. These findings led us to analyze the mechanism to determine the subcellular localization of BEGAIN in neurons. Green fluorescent protein (GFP)-tagged BEGAIN appeared first in nuclei and subsequently accumulated at dendrites. Approximately 75 and $90 \%$ of GFP-BEGAIN clusters were colocalized with synaptophysin and PSD-95/SAP90, respectively. GFP-protein containing only the $\mathrm{N}$-terminal region also formed foci in nuclei and
\end{abstract}

clusters at dendrites. The N-terminal BEGAIN was not precisely targeted to synapses, although it was partially localized at synapses, possibly through dimer formation with endogenous BEGAIN. The truncated form of PSD-95/SAP90 containing the guanylate kinase domain blocked synaptic targeting of BEGAIN but did not affect cluster formation at dendrites. NMDA receptor antagonists blocked localization of GFP-BEGAIN at synapses but did not affect recruitment to dendrites. These results suggest that BEGAIN is recruited to dendrites by the $\mathrm{N}$-terminal region independently of NMDA receptor activity and that synaptic targeting of BEGAIN depends on NMDA receptor activity and may be mediated by interaction with PSD-95/SAP90.

Key words: BEGAIN; PSD-95/SAP90; NMDA receptor; synapse; nucleus; dendrite
NMDA receptors are ionotropic glutamate receptors that play essential roles for synaptic plasticity. Recent studies have revealed that various proteins interact either directly or indirectly with NMDA receptors and are involved in the accumulation of the receptors at postsynaptic sites and in signals triggered by neurotransmission. To clarify the molecular mechanism of synaptogenesis and synaptic remodeling of excitatory synapses, it is important to understand the biochemical and biophysical characters of proteins associated with NMDA receptors. Postsynaptic density (PSD)-95/synapse-associated protein (SAP) 90 is the prototypic synaptic membrane-associated protein that induces clustering of NMDA receptors and binds signaling molecules, including tyrosine kinase and regulators for small GTP-binding proteins (Cho et al., 1992; Kistner et al., 1993; Kornau et al., 1995; Chen et al., 1998; Kim et al., 1998; Hata and Takai, 1999; Tezuka et al., 1999). PSD-95/SAP90 also binds a cytoskeleton adapter protein, guanylate kinase-associated protein (GKAP) (also called synapseassociated protein 90/postsynaptic density-95-associated protein and discs large tumor suppressor protein-associated protein), and the complex of PSD-95/SAP90 and GKAP links NMDA receptors to the cytoskeleton (Kim et al., 1996; Naisbitt et al., 1997;

\footnotetext{
Received March 13, 2002; revised March 13, 2002; accepted March 22, 2002.

This study was supported by grants-in-aids for Scientific Research and Special Coordination Funds for Promoting Science and Technology from the Ministry of Education, Culture, Sports, Science, and Technology, a grant from NOVARTIS Foundation (Japan) for the Promotion of Science, and a grant from Yamanouchi Foundation for Research on Metabolic Disorders. We thank Prof. Y. Takai (Osaka University, Osaka, Japan) for critically reading this manuscript, Prof. A. Lamond (University of Dundee, Dundee, UK) for valuable advice, and Dr. Gary Nolan (Stanford University) for phoenix ampho cells.

Correspondence should be addressed to Yutaka Hata, Department of Medical Biochemistry, Graduate School of Medicine, Tokyo Medical and Dental University, 1-5-45 Yushima, Bunkyo-ku, Tokyo 113-8519, Japan. E-mail: yuhammch@med. tmd.ac.jp.

Copyright (C) 2002 Society for Neuroscience $\quad 0270-6474 / 02 / 225354-11 \$ 15.00 / 0$
}

Satoh et al., 1997; Takeuchi et al., 1997; Hirao et al., 2000a). We identified BEGAIN as a PSD-95/SAP90-binding protein (Deguchi et al., 1998). BEGAIN has two isoforms, BEGAIN1 and BEGAIN2, that are different in the $\mathrm{N}$ terminus. BEGAIN1 starts with MGSDQQSSQ and BEGAIN2 starts with MWTGGRRPGRLRRA (single letters indicate amino acids). After these amino acids, BEGAIN1 and BEGAIN2 have an identical sequence. BEGAIN forms a complex with PSD-95/SAP90 and GKAP and is a member of NMDA receptor-associated proteins. These synaptic components are present in mature synapses; however, during synaptogenesis, some components should come to synapses first and others later. We are doing a series of studies on synaptic membrane-associated proteins to determine which region of each molecule is involved in interacting with other components, which region is necessary and sufficient for synaptic localization, and which molecular interaction depends on synaptic activity. These studies will shed light on which proteins play key roles in the assembly of synaptic components.

In this paper, we first report that BEGAIN is localized not only at synapses but also in nuclei in neurons through immunohistochemistry and subcellular fractionation. BEGAIN is localized only in nuclei in epithelial cells, when expressed exogenously. We suppose that neurons have a mechanism to determine the extranuclear localization of BEGAIN. To clarify the mechanism, we have examined which regions of BEGAIN are involved in nuclear and extranuclear localization and whether extranuclear localization of BEGAIN depends on NMDA receptor activity. BEGAIN has two putative nuclear localization signals in the $\mathrm{N}$-terminal region. Consistently, the $\mathrm{N}$-terminal region is involved in nuclear localization. The $\mathrm{N}$-terminal region also mediates recruitment from nuclei to dendrites, but the $\mathrm{N}$-terminal region is not sufficient for synaptic localization. The truncated 
form of PSD-95/SAP90 containing the guanylate kinase (GK) domain blocks synaptic targeting of BEGAIN. These findings suggest that interaction with PSD-95/SAP90 is involved in synaptic targeting of BEGAIN. Furthermore, recruitment of BEGAIN from nuclei to dendrites does not depend on NMDA receptor activity, but targeting to synapses does depend on NMDA receptor activity.

\section{MATERIALS AND METHODS}

Plasmid construction. Various expression vectors were constructed by conventional molecular biology techniques and the PCR method using pLGFPC (Clontech, Palo Alto, CA), pSindRep5 (Invitrogen, Carlsbad, CA), pGex5X-3 (Amersham Biosciences, Piscataway, NJ), and pClneo Myc. pClneo Myc BEGAIN1, BEGAIN2, and pcDNA BEGAIN have been described previously (Deguchi et al., 1998). A linker was ligated to HindIII/BamHI sites of pLGFPC to generate pLGFPC-2 with additional cloning sites. The PCR product (sense primer, actagttttggcaccaaaatcaacg; antisense primer, gcatgcacgcgtgacgtctctagacttgtacagctcgtcca; and template, pLGFPC) was digested in $S p e \mathrm{I} / S p h \mathrm{I}$ and ligated into $X b a \mathrm{I} / S p h \mathrm{I}$ sites of pSindRep5 to generate pSind GFP. pSind GFP BEGAIN-1, -2, -3 , and -4 were constructed from pSind GFP and contain the amino acid residues 1-611, 1-226, 216-415, and 407-611 of BEGAIN2 (GenBank accession number NM024163), respectively. pGex 5X-3 BEGAIN-8 contained the amino acid residues 20-226, which are common for BEGAIN1 and BEGAIN2. pLGFPC BEGAIN-2 and -4 were constructed from pLGFPC-2 and contain the same amino acid residues as pSind GFP BEGAIN-2 and -4. Oligonucleotides (ctagcccccaacatggagcagaaacttatcagcgaggaggacctgacgcgtctagag and catgctctagacgcgtcaggtcetcctcgctgataag tttctgctccatgttgggggg) were phosphorylated, annealed, and ligated to $X b a \mathrm{I} / S p h \mathrm{I}$ sites of pSindRep5 to generate pSind Myc. pSind Myc PSD95-1 and -2 contain the amino acid residues 1-724 and 294-724 of PSD-95/SAP90, respectively. pCMV Myc PSD-95-1 and pClneo Myc PSD-95-4 contain the amino acid residues 1-724 and 435-724 of PSD95/SAP90, respectively.

Antibodies. The antibody against the $\mathrm{C}$ terminus of BEGAIN (antiBEGAIN-C) has been described previously (Deguchi et al., 1998). The rabbit anti-BEGAIN-N antibody was raised against the product of pGex5X-3 BEGAIN-8. Sheep polyclonal anti-Myc antibody was raised against the synthetic peptide, Glu-Gln-Lys-Ile-Ser-Glu-Glu-Asp-LeuAsn-Ser-Ala-Val-Asp. Mouse monoclonal anti-synaptophysin and antiGFP antibodies were obtained from Roche Molecular Biochemicals (Mannheim, Germany) and Clontech (Palo Alto, CA), respectively. Mouse monoclonal anti-PSD-95/SAP90 (K28/86.2) antibodies were purchased from Upstate Biotechnology (Lake Placid, NY). The secondary antibodies for dual labeling were obtained from Chemicon International (Temecula, CA).

Cell cultures and stable transformants. Phoenix ampho, Madin-Darby canine kidney, HeLa, and COS cells were cultured in DMEM supplemented with $10 \%$ FBS, $100 \mathrm{U} / \mathrm{ml}$ penicillin, and $100 \mu \mathrm{g} / \mathrm{ml}$ streptomycin. For normal rat kidney cells, calf serum was used instead of FBS, and nonessential amino acids were added. Baby hamster kidney cells were cultured in MEM supplemented with 5\% FBS, $100 \mathrm{U} / \mathrm{ml}$ penicillin, and $100 \mu \mathrm{g} / \mathrm{ml}$ streptomycin. For the glycerol density gradient experiment, we used stable transformants of HeLa cells expressing GFP-BEGAIN-2 and -4 . Phoenix ampho cells were transfected with pLGFP BEGAIN-2 and -4 using the Mammalian Transfection Kit (Stratagene, La Jolla, CA). The medium was collected $2 \mathrm{~d}$ after transfection and used to infect $\mathrm{HeLa}$ cells. To generate stable cell lines, the infected cells were cultured in the medium containing $1 \mathrm{mg} / \mathrm{ml}$ Geneticin (Sigma-Aldrich, St. Louis, MO).

Hippocampal neuron culture and hippocampal slice culture. All procedures related to the care and treatment of animals were in accordance with institutional and National Institutes of Health guidelines. Hippocampal neuron cultures were performed from embryonic day $18 \mathrm{em}-$ bryos as described previously (Takeuchi et al., 1997; Goslin et al., 1998). Hippocampal slice was obtained from postnatal day (P) 6 or P8 rats and cultured on Millicell CM culture plate inserts (Millipore, Bedford, MA) in MEM containing 25\% (v/v) HBSS, $6.5 \mathrm{gm} / 1$ glucose, $100 \mathrm{U} / \mathrm{ml}$ penicillin, $100 \mu \mathrm{g} / \mathrm{ml}$ streptomycin, and $25 \%$ (v/v) horse serum at $32^{\circ} \mathrm{C}$ under $5 \% \quad \mathrm{CO}_{2}$. To transfect primary cultured hippocampal neurons, endotoxin-free plasmids were prepared with the EndoFree Plasmid Kit (Qiagen, Hilden, Germany), and $0.2 \mu \mathrm{g}$ of DNA was transfected using Effectene Transfection Reagent (Qiagen) to neurons $3 \mathrm{~d}$ after plating. Seven days after transfection, neurons were fixed and immunostained with the appropriate antibodies.
Immunofluorescence and immunohistochemistry. Hippocampal neurons were fixed with $4 \%(w / v)$ paraformaldehyde for $15 \mathrm{~min}$, blocked with 50 $\mathrm{mm}$ glycine in PBS for $30 \mathrm{~min}$, and permeabilized with $0.25(\mathrm{w} / \mathrm{v}) \%$ Triton X-100 in PBS for 5 min. Alternatively, hippocampal neurons were fixed in ice-cold methanol for $20 \mathrm{~min}$ at $-20^{\circ} \mathrm{C}$ as described (Allison et al., 2000). After cells were blocked with PBS containing 10\% (w/v) BSA, they were incubated with the first antibody in PBS containing $3 \%(w / v)$ BSA overnight, washed with PBS, and incubated with the second antibody in PBS containing 3\% (w/v) BSA for $1 \mathrm{hr}$. After the samples were washed with PBS, they were embedded in $95 \%$ (w/v) glycerol in PBS. Immunohistochemical studies were performed as described (Lee et al., 1998). Wistar rats (4 weeks old) were deeply anesthetized with sodium pentobarbital $(60 \mathrm{mg} / \mathrm{kg}$, i.p.) and perfused with $4 \%$ (w/v) paraformaldehyde in $0.1 \mathrm{M}$ phosphate buffer (PB), $\mathrm{pH}$ 7.4. Brains were removed and postfixed in the same fixative, immersed with $10 \%(\mathrm{w} / \mathrm{v}), 20 \%(\mathrm{w} / \mathrm{v})$, and $30 \%(\mathrm{w} / \mathrm{v})$ sucrose in $0.1 \mathrm{M} \mathrm{PB}, \mathrm{pH} 7.4$, sequentially, and frozen at $-80^{\circ} \mathrm{C}$. Then, $5 \mu \mathrm{m}$ sections were prepared, washed in $0.1 \mathrm{M} \mathrm{PB}$, blocked with 0.1 M PB containing 5\% goat serum and $0.2 \%(\mathrm{w} / \mathrm{v})$ Triton X-100 for $2 \mathrm{hr}$, and incubated with the first antibodies at $4^{\circ} \mathrm{C}$ overnight. After they were washed with $0.1 \mathrm{M}$ PB four times, bound antibodies were detected with the second antibodies at room temperature for $3 \mathrm{hr}$. Then, the samples were counterstained with $0.1 \mu \mathrm{g} / \mathrm{ml}$ Hoechst 33342 for $10 \mathrm{~min}$ when indicated, washed with $0.1 \mathrm{M} \mathrm{PB}$, and embedded in $50 \%(\mathrm{w} / \mathrm{v})$ glycerol in $0.1 \mathrm{M} \mathrm{PB}$. For methanol fixation, brains were quickly removed from decapitated rats and frozen in powdered dry ice. Sections were cut at $10 \mu \mathrm{m}$ thickness on a cryostat (Leica CM1800), mounted on aminopropyltriethoxysilane-coated glass slides (Matsunami Glass, Osaka, Japan), fixed in ice-cold methanol for $20 \mathrm{~min}$ at $-20^{\circ} \mathrm{C}$, and dried with a stream of cold air. The images were obtained by confocal microscopies (Olympus FV300-BX and Zeiss LSM510).

Isolation of nuclei from rat brains. Isolation of nuclei from rat brains and immunostaining of the nuclear fraction were performed according to the previously reported protocols with modifications (Wu et al., 1995; Rickwood et al., 1997) (see Fig. 2A). Rat brains were removed and homogenized in 9 vol of homogenizing buffer $[0.25 \mathrm{M}$ sucrose, $5 \mathrm{~mm}$ $\mathrm{MgCl}_{2}, 10 \mathrm{~mm}$ Tris/ $\mathrm{HCl}, \mathrm{pH} 7.4,1 \mathrm{~mm}$ phenylmethylsulfonyl fluoride (PMSF)] in a Potter-Elvehjem homogenizer using eight to nine strokes driven at $1000 \mathrm{rpm}$. After the homogenate was filtered through four layers of gauze, it was centrif uged at $600 \times g$ for $10 \mathrm{~min}$ at $5^{\circ} \mathrm{C}$. The pellet $\left(\mathrm{P}_{1}\right)$ was resuspended in half the original volume of the homogenizing buffer and centrif uged again. The pellet of crude nuclei was resuspended and homogenized in 9 vol of $2.2 \mathrm{M}$ sucrose, $1 \mathrm{mM} \mathrm{MgCl}_{2}, 10 \mathrm{~mm}$ Tris/HCl, pH 7.4, 1 mM PMSF in a Potter-Elvehjem homogenizer using five to six strokes driven at $1000 \mathrm{rpm}$. The suspension of nuclei was centrifuged at $80,000 \times g$ for $80 \mathrm{~min}$ at $5^{\circ} \mathrm{C}$ in a swing-bucket rotor. The resulting mixed membrane (M.M.) fraction occurring as a top layer was removed, and the pellet was collected as isolated nuclei $\left(\mathrm{P}_{2}\right)$. Then, freshly isolated nuclei were fixed in ice-cold $4 \%$ (w/v) paraformaldehyde in PBS for $30 \mathrm{~min}$ at $4^{\circ} \mathrm{C}$ and were applied to poly-L-lysine-coated cover glasses for $30 \mathrm{~min}$ at room temperature. After they were washed once with $50 \mathrm{~mm}$ glycine in PBS, the nuclei were incubated with $5 \%(\mathrm{w} / \mathrm{v})$ goat serum, $1.5 \%(\mathrm{w} / \mathrm{v}) \mathrm{BSA}$, and $1.5 \%(\mathrm{w} / \mathrm{v})$ Triton X-100 in PBS for $20 \mathrm{~min}$ and were incubated with the first antibodies at $4^{\circ} \mathrm{C}$ overnight. After the nuclei were washed with PBS, they were incubated with second antibodies for $2 \mathrm{hr}$ at room temperature, stained with $0.1 \mu \mathrm{g} / \mathrm{ml}$ Hoechst 33342 for $10 \mathrm{~min}$, and embedded in $95 \%$ glycerol (w/v) in PBS.

Subcellular fractionation of HeLa cells. HeLa cells were treated with $0.25 \%(\mathrm{w} / \mathrm{v})$ trypsin and $1 \mathrm{~mm}$ EDTA for $5 \mathrm{~min}$ at $37^{\circ} \mathrm{C}$ and collected. The cells were washed with ice-cold PBS twice and resuspended in a 0.5 $\mathrm{ml} / 10 \mathrm{~cm}$ dish of TM-2 buffer $(10 \mathrm{~mm}$ Tris $/ \mathrm{HCl}, \mathrm{pH} 7.4$, with $2 \mathrm{~mm}$ $\mathrm{MgCl}_{2}$ and $0.5 \mathrm{~mm}$ PMSF). The resuspended cells stood at room temperature for $1 \mathrm{~min}$ and were incubated in ice-water for $5 \mathrm{~min}$. Triton $\mathrm{X}-100$ was added to a final concentration of $0.5 \%(\mathrm{w} / \mathrm{v})$. The cells were incubated in ice-water for an additional $5 \mathrm{~min}$ and sheared by three passages through a 22 gauge needle. The nuclei were examined in a phase-contrast microscope and isolated from the cytosol by centrifugation at $980 \times g$ for $10 \mathrm{~min}$ at $4^{\circ} \mathrm{C}$. The pellet was rinsed with $0.5 \mathrm{ml}$ of TM-2 buffer twice and designated as the nuclear fraction.

Sindbis virus production and infection. Capped in vitro transcripts and helper RNA were synthesized from various linearized pSind GFP constructs and $\mathrm{DH}(26 \mathrm{~S})$ template (Invitrogen) using a RiboMAX Large Scale RNA production system (Promega, Madison, WI) and transfected into baby hamster kidney cells by electroporation with a GenePulser (Bio-Rad, Hercules, CA). Two days later, the medium was collected and centrifuged at $400 \times g$ for $5 \mathrm{~min}$; the supernatant was centrifuged at 

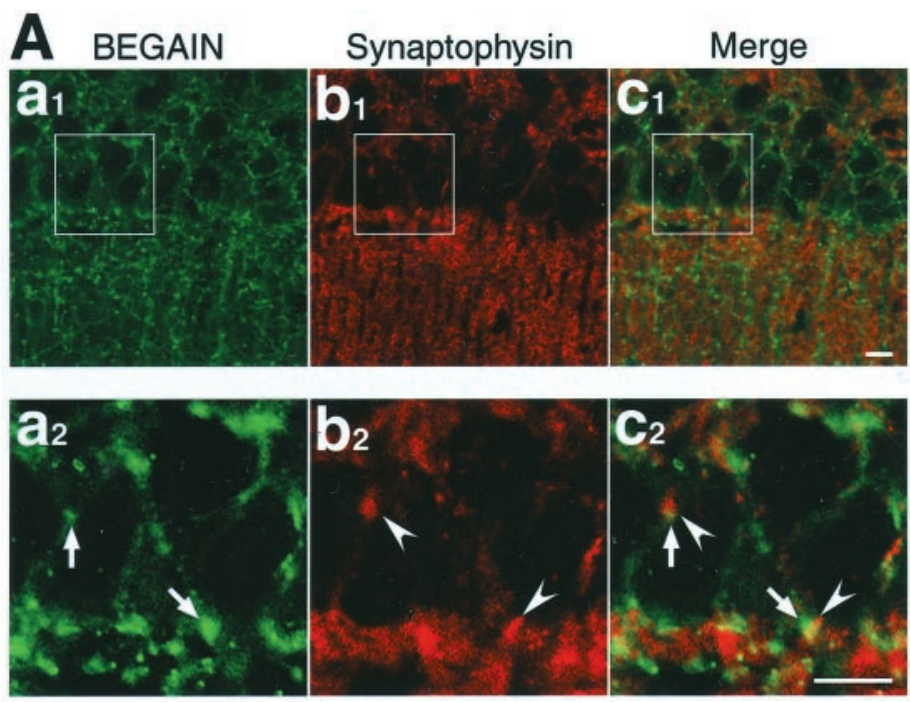

Figure 1. Immunohistochemistry of BEGAIN in rat hippocampus. $A$, Laser confocal image of paraformaldehyde-fixed rat hippocampus CA1 region. Rats were perfused with paraformaldehyde, and brains were further postfixed. Sections were stained with anti-BEGAIN-N and the anti-synaptophysin antibodies. $a$, BEGAIN (arrows); $b$, synaptophysin (arrowheads); $c$, superimposed image. $a 2, b 2$, and $c 2$ show the demarcated areas in $a 1, b 1$, and $c 1$ at higher magnification. Scale bars, $10 \mu \mathrm{m}$. $B$, Laser confocal image of methanol-fixed rat hippocampus CA1 region. Rat brains were frozen in powdered dry ice. Sections were fixed with ice-cold methanol and stained with anti-BEGAIN-N and anti-synaptophysin antibodies and with Hoechst 33342. a, BEGAIN (arrows); $b$, synaptophysin (arrowheads); c, Hoechst 33342; $d$, superimposed image. $a 2, b 2$, c2, and $d 2$ show the demarcated areas in $a 1, b 1, c 1$, and $d 1$ at higher magnification. Scale bar, $10 \mu \mathrm{m}$.
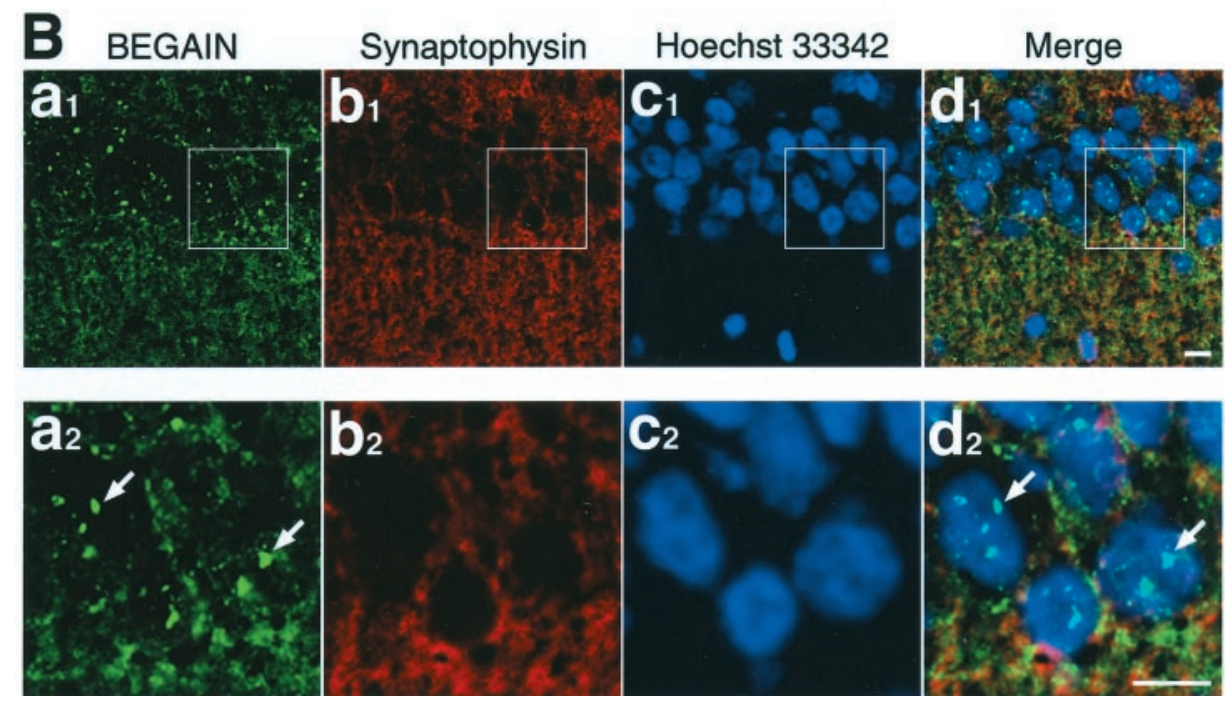

$113,000 \times g$ for $90 \mathrm{~min}$. The pellet was collected, resuspended in $200 \mu \mathrm{l}$ of the medium, and stocked at $-80^{\circ} \mathrm{C}$. Primary cultured hippocampal neurons were infected using 3-5 $\mu \mathrm{l}$ of the virus stock per $500 \mu \mathrm{l}$ of the culture medium $10 \mathrm{~d}$ after plating. For double infection, 3-5 $\mu \mathrm{l}$ of each virus stock was added to $500 \mu \mathrm{l}$ of the culture medium at the same time. Hippocampal slices were infected using $1 \mu \mathrm{l}$ of the virus stock per each slice $7 \mathrm{~d}$ after plating. All experiments using primary cultured hippocampal neurons were repeated independently at least three times.

Image acquisition and quantification. For quantification of cluster number and size, primary cultured hippocampal neurons were observed $24 \mathrm{hr}$ after the infection, and confocal images were obtained using an Olympus FV300-BX $40 \times$ objective with sequential acquisition at $1024 \times 1024$ pixels resolution and then converted to $512 \times 512$ pixels resolution. Each image was averaged four times and taken with the confocal aperture set at 3 . Neurons expressing GFP-BEGAIN-1 or -2 were chosen at random from two to three cover glasses from three independent preparations. Measurements were performed using NIH image 1.61. We defined signals as clusters if they had the following properties: (1) peak fluorescence levels $50 \%$ greater than the maximal fluorescence levels of diffuse dendritic signals in the vicinity; (2) 3-30 pixels in size; and (3) location between 10 and $100 \mu \mathrm{m}$ from the soma. We counted the number from 700 $\mu \mathrm{m}$ of the dendrites for each neuron. Diameters of clusters were calculated from the areas of clusters.

Glycerol density gradient. HeLa cells expressing GFP-BEGAIN-2 or -4 of three $10 \mathrm{~cm}$ plates were homogenized in $0.4 \mathrm{ml}$ of buffer A [20 mM HEPES/KOH, pH 7.4, $100 \mathrm{~mm} \mathrm{NaCl,} \mathrm{0.5 \%} \mathrm{(w/v)} \mathrm{Triton} \mathrm{X-100,} \mathrm{and} \mathrm{2 \%}$ $(\mathrm{v} / \mathrm{v})$ glycerol], and centrifuged at $100,000 \times g$ for $30 \mathrm{~min}$. The supernatant was charged on $4.4 \mathrm{ml}$ of $5-25 \%(\mathrm{v} / \mathrm{v})$ glycerol density gradient in buffer A, overlaid with $0.1 \mathrm{ml}$ of buffer $\mathrm{A}$, and centrifuged at $4^{\circ} \mathrm{C}$ at $100,000 \times g$ for $17 \mathrm{hr}$. Eighteen fractions were collected from the gradient and analyzed by immunoblotting with the anti-GFP antibody.

Coimmunoprecipitation of BEGAIN-1 and -2. COS cells were transfected with pClneo Myc BEGAIN-1 and -2 using the DEAE-dextran method. Forty-eight hours later, the cells of two $10 \mathrm{~cm}$ plates were collected and homogenized in $1 \mathrm{ml}$ of $20 \mathrm{~mm}$ HEPES/NaOH, pH 7.4, containing $100 \mathrm{~mm} \mathrm{NaCl}$ and $1 \%(w / v)$ Triton X-100. After centrifugation at $100,000 \times g$ for $15 \mathrm{~min}$ at $4^{\circ} \mathrm{C}$, the supernatant was collected, and $0.45 \mathrm{ml}$ of the supernatant was incubated with $10 \mu \mathrm{l}$ of the antiBEGAIN-C serum or the preimmune serum and precipitated with $7.5 \mu \mathrm{l}$ of protein-G Sepharose 4 Fast Flow (Amersham Biosciences). The precipitates were immunoblotted with the anti-Myc antibody.

\section{RESULTS}

\section{Synaptic and nuclear localization of BEGAIN in rat brains}

First, we detected BEGAIN in rat hippocampus with the affinitypurified anti-BEGAIN-N antibody using immunofluorescence microscopy. In paraformaldehyde-fixed sections, BEGAIN was detected around pyramidal neurons and colocalized with synaptophysin (Fig. 1 $A$ ). In methanol-fixed sections, BEGAIN showed foci in pyramidal neuron nuclei (Fig. $1 B$ ). Immunohistochemistry with the anti-BEGAIN-C antibody likewise showed synaptic localization in paraformaldehyde-fixed sections and nuclear local- 
A

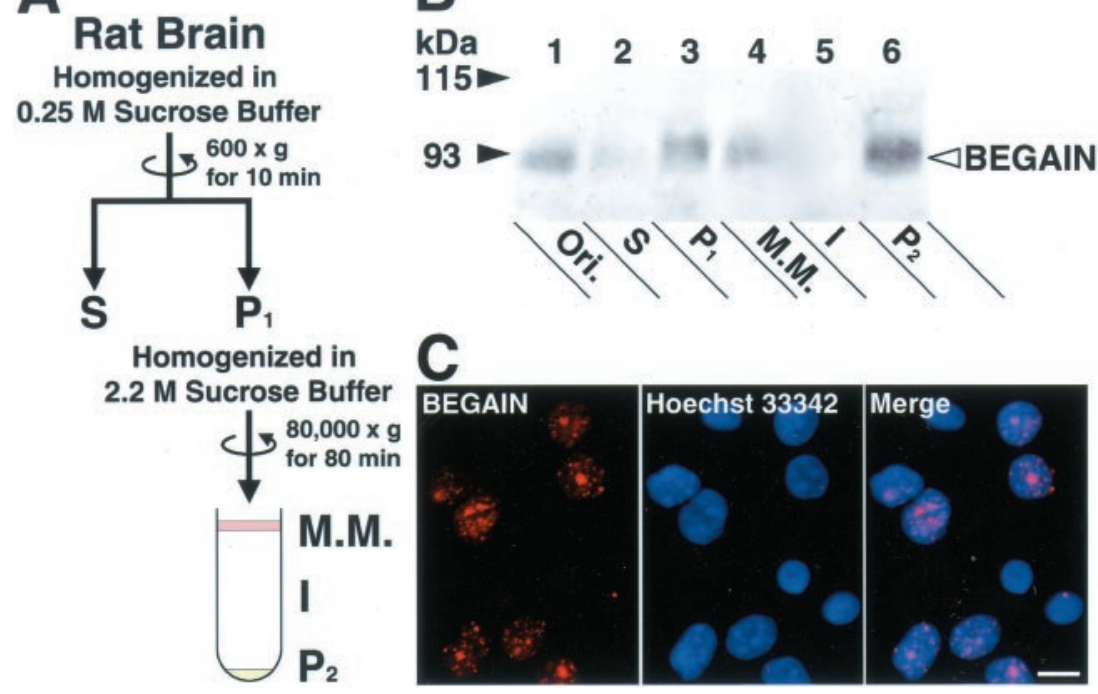

Figure 2. BEGAIN in nuclear fraction. $A$, Scheme of the subcellular fractionation. $B$, BEGAIN in subcellular fractionation of rat brain. Subcellular fractionation was performed using rat brain, and the comparable amount of each fraction was immunoblotted with anti-BEGAIN-C antibody. Ori., Original homogenate before fractionation; $S$, synaptosomal fraction; $P_{l}$, crude nuclear fraction; $M . M$., mixed membrane fraction containing mainly Golgi and endoplasmic reticulum membranes and partially contaminated with nuclei; $I$, intermediate fraction; and $P_{2}$, nuclear fraction. $C$, BEGAIN in $\mathrm{P}_{2}$ fraction. $\mathrm{P}_{2}$ fraction was fixed with paraformaldehyde and applied on the cover glass. The sample was stained with anti-BEGAIN-N antibody and Hoechst 33342. Scale bar, $10 \mu \mathrm{m}$. ization in methanol-fixed sections (data not shown). To confirm nuclear localization, we performed subcellular fractionation to isolate neuronal nuclei from rat brains (Fig. $2 A$ ). Synaptosomal and $\mathrm{P}_{1}$ fractions contained BEGAIN (Fig. $2 B$ ). The further fractionation of $\mathrm{P}_{1}$ fraction gave M.M., intermediate $(I)$, and $\mathrm{P}_{2}$ fractions. BEGAIN was detected in M.M. and $\mathrm{P}_{2}$ fractions. The staining of $\mathrm{P}_{2}$ fraction with Hoechst 33342 indicated isolated nuclei, in which BEGAIN formed foci (Fig. $2 C$ ). The staining of

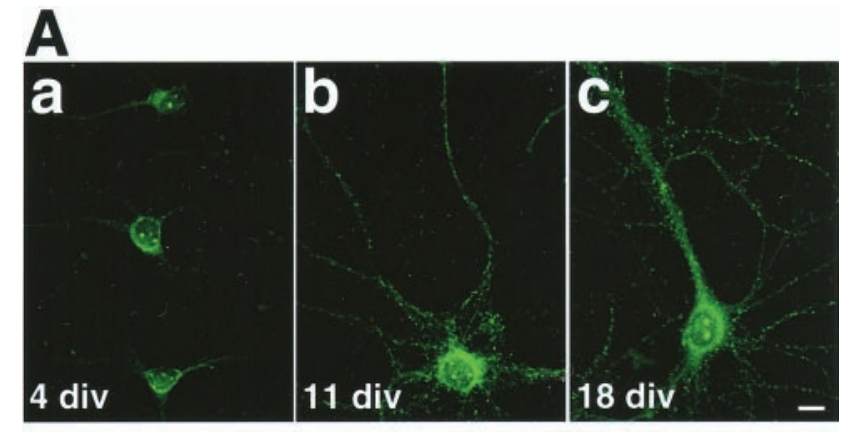

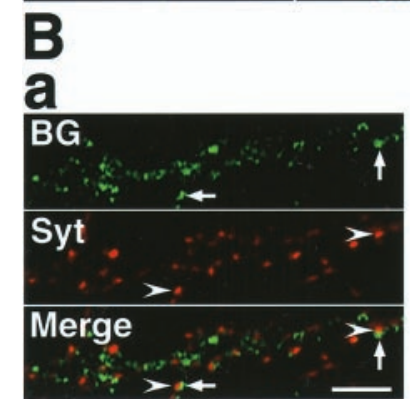

Methanol

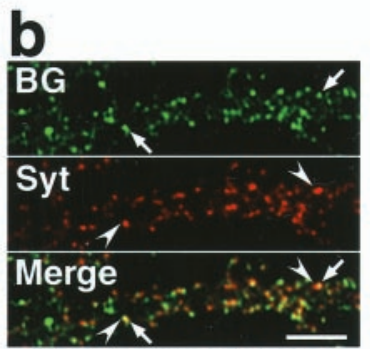

Paraformaldehyde
Figure 3. BEGAIN in rat primary cultured hippocampal neurons. $A$, Laser confocal images of rat primary cultured hippocampal neurons were fixed with ice-cold methanol at various stages and stained with antiBEGAIN-N antibody and FITC-conjugated secondary antibody. $a$, 4 div; $b, 11 \mathrm{div} ; c, 18 \mathrm{div}$. Scale bar, $10 \mu \mathrm{m}$. B, Synaptic localization of BEGAIN. Rat primary cultured hippocampal neurons were fixed with either methanol or paraformaldehyde at 18 div and stained with anti-BEGAIN-N and anti-synaptophysin antibodies. $a$, Fixed with methanol. $b$, Fixed with paraformaldehyde. BG, BEGAIN (arrows); Syt, synaptophysin (arrowheads); Merge, superimposed image. Scale bar, $5 \mu \mathrm{m}$. the M.M. fraction indicated that it was partially contaminated with some nuclei (data not shown).

\section{Distribution of BEGAIN in rat primary cultured hippocampal neurons}

We next examined the distribution of BEGAIN in rat primary cultured hippocampal neurons using anti-BEGAIN-N antibody. At $4 \mathrm{~d}$ in vitro (DIV), BEGAIN was detected in the soma and in nuclei (Fig. 3A). At 11 and 18 DIV, BEGAIN was also distributed in neurites. The double immunostaining with anti-BEGAIN-N and anti-synaptophysin antibodies indicated that BEGAIN was colocalized with synaptophysin at 18 DIV (Fig. $3 B$ ). In primary cultured hippocampal neurons, both methanol and paraformaldehyde fixations showed synaptic localization, although the latter more clearly demonstrated accumulation of BEGAIN at synapses than the former.

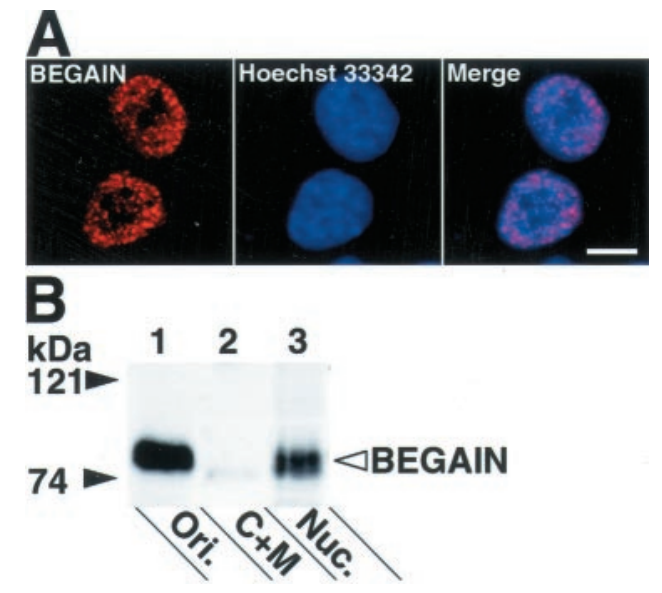

Figure 4. BEGAIN in HeLa Cells. A, BEGAIN in HeLa cells. HeLa cells were transiently transfected with pcDNA BEGAIN and stained with anti-BEGAIN-N antibody and Hoechst 33342. Scale bar, $10 \mu \mathrm{m}$. B, BEGAIN in subcellular fractionation of HeLa cells. HeLa cells were transfected with pcDNA BEGAIN. Subcellular fractionation was performed, and the comparable amount of each fraction was immunoblotted with anti-BEGAIN-N antibody. Ori., Original homogenate; $C+M$, cytosol and membrane fraction; Nuc., nuclear fraction. 

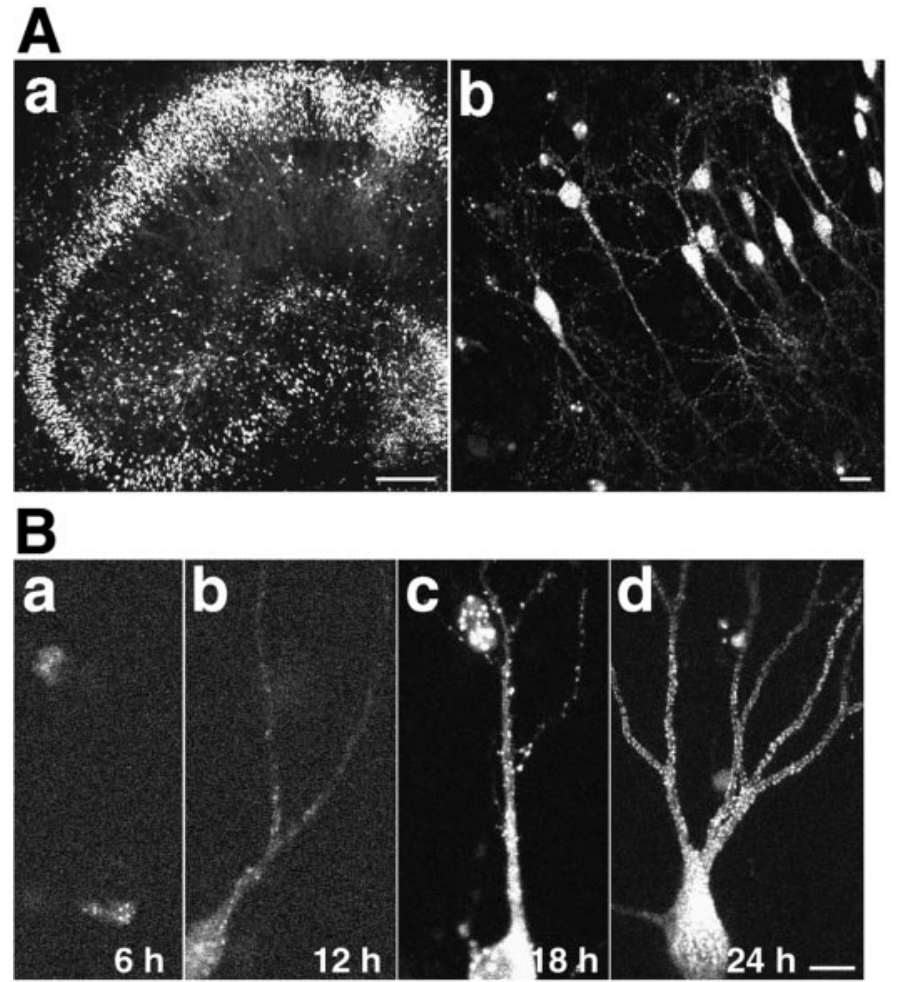

Figure 5. Temporal profile of the expression of GFP-BEGAIN in neurons. $A$, Laser confocal image of a hippocampal slice infected with Sindbis virus to express GFP-BEGAIN-1. a, Overview of a hippocampus. Most pyramidal neurons in CA1 and CA3 and granule neurons in dentate gyrus express GFP-BEGAIN-1. Scale bar, $100 \mu \mathrm{m}$. $b$, Neurons in CA1. Scale bar, $20 \mu \mathrm{m}$. $B$, Temporal profile of expression of GFP-BEGAIN-1 in neurons in a cultured hippocampal slice. $a$, Six hours $(6 h)$ after infection; $b, 12 \mathrm{hr}(12 \mathrm{~h})$ after infection; $c, 18 \mathrm{hr}(18 \mathrm{~h})$ after infection; $d, 24 \mathrm{hr}(24$ $h)$ after infection. Scale bar, $10 \mu \mathrm{m}$.

\section{Distribution of BEGAIN in non-neuronal cells}

On the basis of the findings described above, we concluded that BEGAIN was localized at synapses and in nuclei in neurons. BEGAIN was detected only in nuclei, however, when it was expressed in HeLa cells (Fig. 4A). We examined the nuclear localization of BEGAIN through subcellular fractionation. BEGAIN was recovered in the nuclear fraction (Fig. 4B). To further confirm that BEGAIN was not detected outside nuclei, we also expressed BEGAIN in other non-neuronal cells, including COS, MadinDarby canine kidney, and normal rat kidney cells. In all these cells, BEGAIN was localized only in nuclei (data not shown). These findings suggest that neurons have some mechanism to recruit BEGAIN outside nuclei.

\section{GFP-BEGAIN-1 accumulates first in nuclei in neurons and then at dendrites}

To analyze the mechanism to determine the localization of BEGAIN in neurons, we made use of GFP-tagged BEGAIN. To test whether GFP-BEGAIN was localized similarly to endogenous BEGAIN, we expressed it in neurons. Because hippocampal slice neurons were infected with Sindbis virus very effectively and dendrites were easy to identify, we first expressed GFPBEGAIN in hippocampal slice neurons. Bright foci in nuclei and clusters at dendrites were observed (Fig. $5 A$ ). In the temporal profile study, GFP-BEGAIN foci in nuclei were detected $6 \mathrm{hr}$

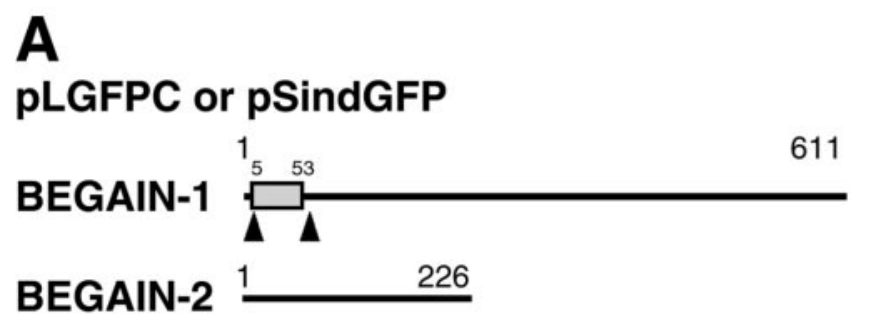

BEGAIN-3 $216 \quad 415$

BEGAIN-4 $407 \quad 611$
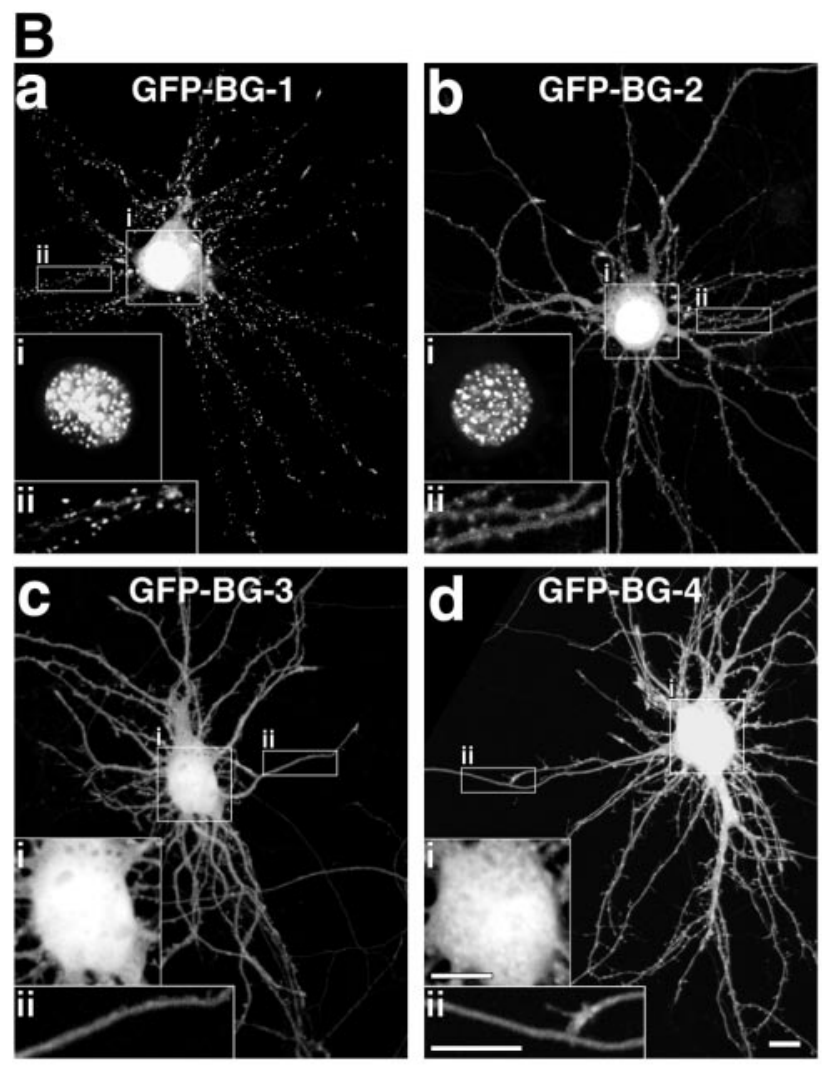

Figure 6. Various GFP-BEGAIN proteins expressed in primary cultured hippocampal neurons. $A$, Scheme of various constructs of BEGAIN. The region containing a leucine zipper is shown as a box. Numbers indicate the numbers of amino acid residues of BEGAIN. Putative nuclear localizing signals are indicated by triangles. B, Various GFPBEGAIN proteins in rat primary cultured hippocampal neurons. Rat primary cultured hippocampal neurons were infected with Sindbis virus and fixed with paraformaldehyde $24 \mathrm{hr}$ later. $a$, GFP-BEGAIN-1; $b$, GFP-BEGAIN-2; $c$, GFP-BEGAIN-3; $d$, GFP-BEGAIN-4. Insets $i$ and $i i$ indicate nuclei and neurites in demarcated areas at higher magnification, respectively. Scale bar, $10 \mu \mathrm{m}$.

after infection (Fig. 5Ba). At $12 \mathrm{hr}$, clusters appeared at dendrites and increased subsequently (Fig. $5 B b-d$ ).

\section{The $\mathbf{N}$-terminal region is involved in nuclear} localization and recruitment of BEGAIN to dendrites

To determine which region was involved in the nuclear and dendritic localization, we prepared GFP-tagged proteins contain- 


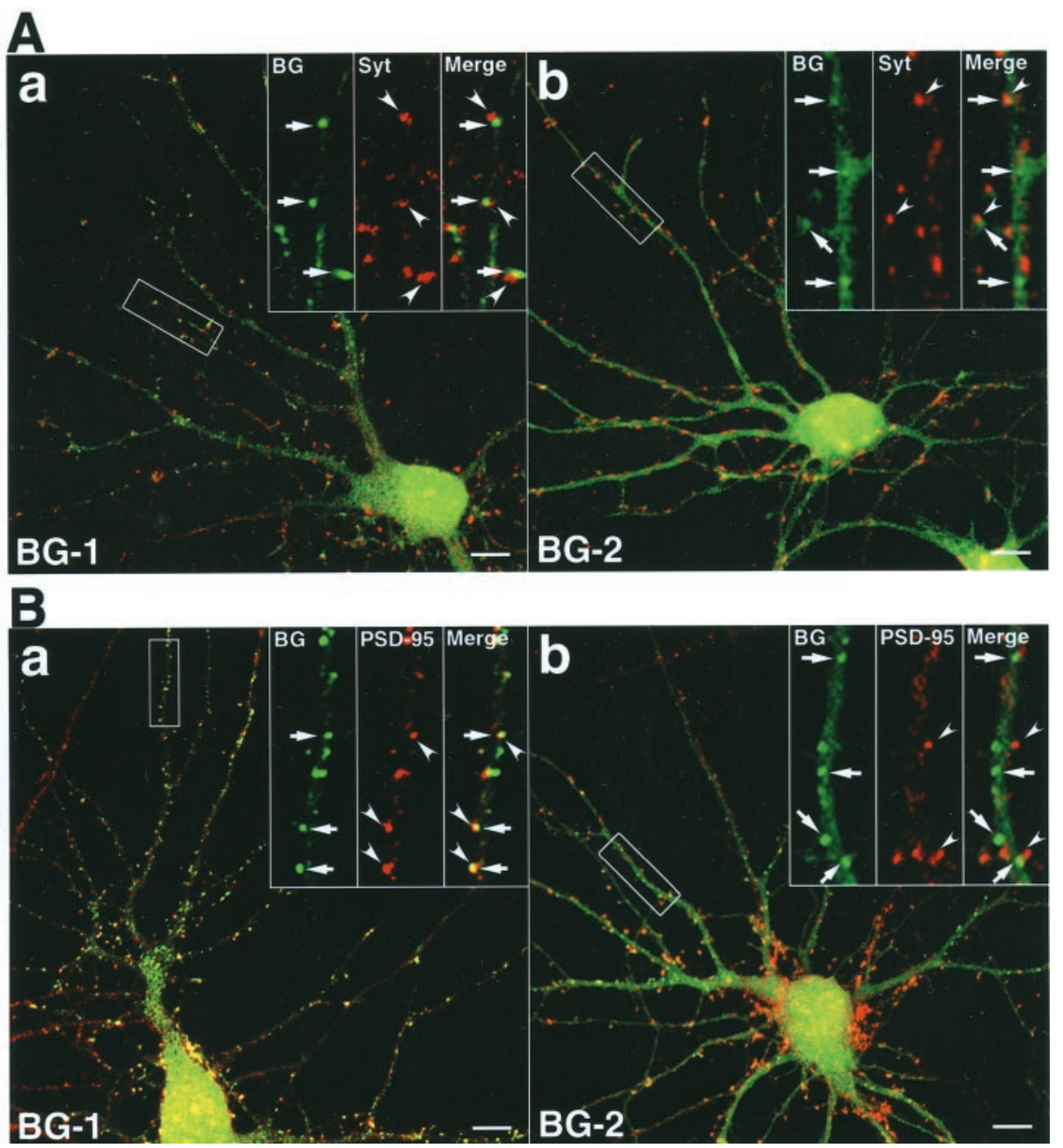

Figure 7. GFP-BEGAIN-1 and -2 with synaptophysin and PSD-95/SAP90 in primary cultured hippocampal neurons. $A$, Primary cultured hippocampal neurons expressing GFP-BEGAIN-1 or -2 were immunostained with anti-synaptophysin antibody. Insets show the demarcated areas at higher magnification. $a$, GFP-BEGAIN-1 and synaptophysin. GFP-BEGAIN-1 was colocalized with synaptophysin. $B G$, GFP-BEGAIN-1 (arrows); Syt, synaptophysin (arrowheads); Merge, superimposed image of GFP-BEGAIN-1 and synaptophysin. $b$, GFP-BEGAIN-2 and synaptophysin. $B G$, GFP-BEGAIN-2 (arrows); Syt, synaptophysin (arrowheads); Merge, superimposed image of GFP-BEGAIN-2 and synaptophysin. Scale bar, $10 \mu \mathrm{m}$. $B$, Primary cultured hippocampal neurons expressing GFP-BEGAIN-1 or -2 were immunostained with anti-PSD-95 antibody. Insets show the demarcated areas at higher magnification. $a$, GFP-BEGAIN-1 and PSD-95/ SAP90. GFP-BEGAIN-1 and PSD-95/SAP90 were colocalized in primary cultured hippocampal neurons. $B G$, GFP-BEGAIN-1 (arrows); PSD-95, PSD-95/SAP90 (arrowheads); Merge, superimposed image of GFP-BEGAIN-1 and PSD95/SAP90. $b$, GFP-BEGAIN-2 and PSD-95/ SAP90. GFP-BEGAIN-2 formed fewer clusters, and $40 \%$ of the clusters were not colocalized with PSD-95/SAP90. BG, GFP-BEGAIN-2 (arrows); PSD-95, PSD-95/SAP90 (arrowheads); Merge, superimposed image of GFP-BEGAIN-2 and PSD95/SAP90. Scale bar, $10 \mu \mathrm{m}$.

\begin{tabular}{lllll}
\hline Table 1. Properties of the clusters of GFP-BEGAIN-1 and -2 & & & \\
& $\begin{array}{l}\text { Size }(\mu \mathrm{m} \text { in } \\
\text { diameter) }\end{array}$ & $\begin{array}{l}\text { Number (per } 10 \mu \mathrm{m} \\
\text { of the dendrite) }\end{array}$ & $\begin{array}{l}\text { Colocalization with } \\
\text { synaptophysin }(\%)\end{array}$ & $\begin{array}{l}\text { Colocalization with } \\
\text { PSD-95/SAP90 }(\%)\end{array}$ \\
\hline BEGAIN-1 & $0.87 \pm 0.37$ & $3.09 \pm 0.62$ & $74.5 \pm 4.0$ & $89.7 \pm 2.1$ \\
& $(9$ neurons) & $(9$ neurons $)$ & $(10$ neurons $)$ & $(7$ neurons $)$ \\
BEGAIN-2 & $0.82 \pm 0.36$ & $1.13 \pm 0.78$ & $55.0 \pm 5.9$ & $61.8 \pm 4.4$ \\
& $(7$ neurons $)$ & $(7$ neurons $)$ & $(6$ neurons $)$ & $(6$ neurons $)$ \\
Significant difference & None & $<0.001$ & $<0.01$ & $<0.005$
\end{tabular}

The number and size of the clusters were quantified using NIH Image as described in Materials and Methods. Size is described as a diameter calculated from the area. Number is described per $10 \mu \mathrm{m}$ of the dendrite. The numbers of neurons analyzed are indicated in the parentheses. All data were expressed as mean \pm SEM. The Student's paired $t$ test was used when appropriate to examine the statistical significance of the differences between groups.

ing various regions of BEGAIN (Fig. 6A). We expressed these GFP-constructs in rat primary cultured hippocampal neurons. GFP-BEGAIN-2 containing the N-terminal region was accumulated in nuclei and at dendrites like GFP-BEGAIN-1 (Fig. $6 B a, b)$. In contrast, GFP-BEGAIN-3 and -4 were distributed diff usely in the soma and neurites and did not form clusters at dendrites (Fig. $6 B c, d$ ). These data indicate that the $\mathrm{N}$-terminal region of BEGAIN is involved in nuclear localization and recruitment to dendrites in neurons. In HeLa and MadinDarby canine kidney cells, the N-terminal region of BEGAIN was localized in nuclei and formed foci, suggesting that the nuclear localizing signal in this region determines the subcel- lular localization of BEGAIN in non-neuronal cells (data not shown).

\section{GFP-BEGAIN-1 is localized at synapses and the $\mathbf{N}$ - terminal region is not sufficient for targeting to synapses}

We focused on GFP-BEGAIN-1 and -2 and tested whether they were localized at synapses. We immunostained neurons expressing GFP-BEGAIN-1 or -2 with the anti-synaptophysin antibody. GFP-BEGAIN-1 was apposed to the accumulation of synaptophysin, suggesting that GFP-BEGAIN-1 was localized at postsynaptic sites (Fig. 7Aa). GFP-BEGAIN-2 formed fewer clusters 

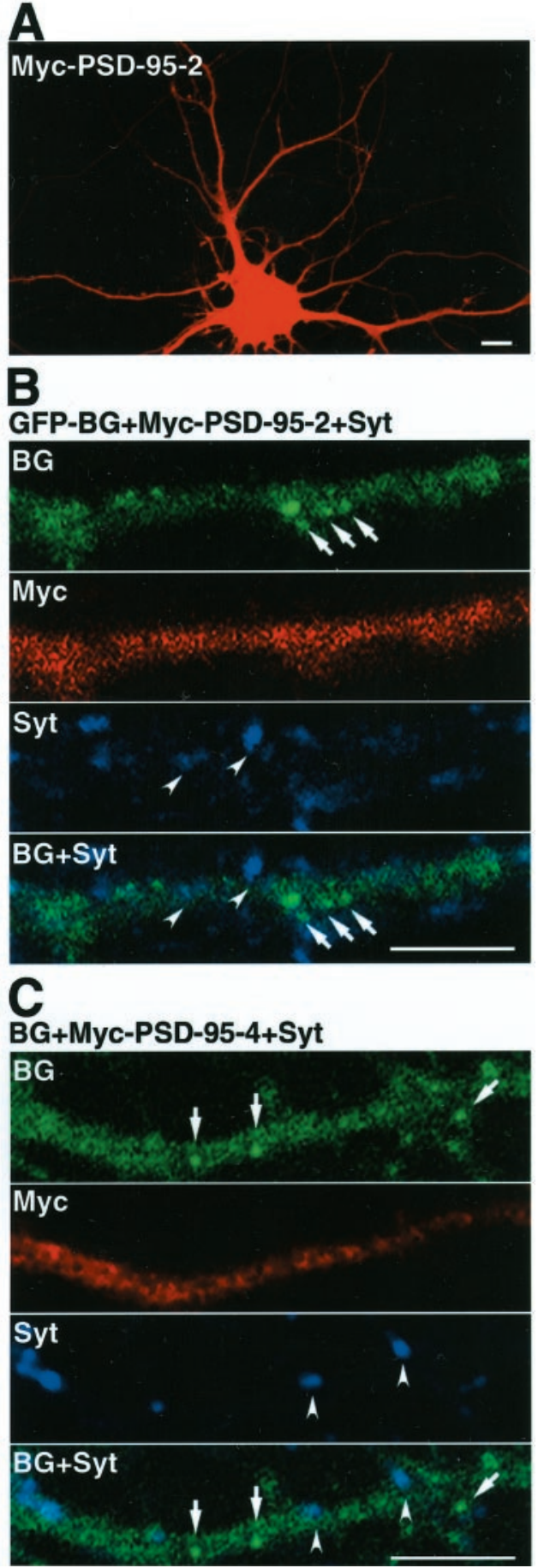

Figure 8. Effect of truncated forms of PSD-95/SAP90 containing the GK domain on synaptic targeting of BEGAIN. $A$, Myc-PSD-95-2 in a primary cultured hippocampal neuron. Primary cultured hippocampal neurons were infected with Sindbis virus. Twenty-four hours after infection, Myc-PSD-95-2 in a neuron was detected with sheep anti-Myc antibody and visualized with rhodamine-conjugated anti-sheep IgG secondary antibody. Myc-PSD-95-2 was diffusely distributed in a neuron. Scale bar, 10 $\mu \mathrm{m}$. B, Localization of GFP-BEGAIN-1 coexpressed with Myc-PSD95-2 in a primary cultured hippocampal neuron. A primary cultured hippocampal neuron expressing GFP-BEGAIN-1 and Myc-PSD-95-2 was immunostained with sheep anti-Myc and mouse anti-synaptophysin antibodies and visualized with rhodamine-conjugated anti-sheep and Cy5conjugated anti-mouse $\operatorname{IgG}$ secondary antibodies. Scale bar, $5 \mu \mathrm{m}$. $B G$, GFP-BEGAIN-1 (arrows); Myc, Myc-PSD-95-2; Syt, synaptophysin (arrowheads); $B G+$ Syt, superimposed image of GFP-BEGAIN-1 and than GFP-BEGAIN-1 (Fig. 7Ab). The numbers and sizes of clusters formed by GFP-BEGAIN-1 and -2 are summarized in Table 1. Forty-five percent of GFP-BEGAIN-2 clusters were not colocalized with synaptophysin. We also determined what population of GFP-BEGAIN-1 or -2 clusters was associated with PSD-95/SAP90. Almost 90\% of GFP-BEGAIN-1 clusters were colocalized with PSD-95/SAP90 (Fig. 7Ba). In contrast, $40 \%$ of GFP-BEGAIN-2 clusters were not associated with PSD-95/ SAP90 (Fig. 7Bb). These findings suggest that the N-terminal region of BEGAIN is not sufficient for targeting to synapses.

\section{Truncated forms of PSD-95/SAP90 containing the GK domain block the synaptic targeting of BEGAIN}

BEGAIN interacts with the GK domain of PSD-95/SAP90 by its C-terminal region (Deguchi et al., 1998). This interaction may be necessary for the synaptic targeting of BEGAIN. We expressed Myc-tagged protein containing the third PSD-95/Dlg-A/ZO-1 (PDZ), SH3, and GK domains of PSD-95/SAP90 (Myc-PSD95-2) using Sindbis virus in neurons. Myc-PSD-95-2 was distributed diffusely in the soma and neurites as in a previous report (Craven et al., 1999) (Fig. 8A). In the presence of Myc-PSD-95-2, GFP-BEGAIN-1 still formed clusters at dendrites (Fig. $8 B$ ); however, these clusters of GFP-BEGAIN-1 were not apposed to the accumulation of synaptophysin. Myc-PSD-95-1 containing the full length of PSD-95/SAP90 formed clusters at dendrites (data not shown). GFP-BEGAIN-1 was colocalized with MycPSD-95-1 and still apposed to synaptophysin at synapses (data not shown). We further examined whether the truncated form of PSD-95/SAP90 containing the SH3 and GK domains affected the localization of the endogenous BEGAIN. For this purpose, we transfected neurons with pClneo Myc PSD-95-4 with lipofection, so that neurons could be maintained for a long time. Seven days after transfection, neurons were immunostained with rabbit antiBEGAIN-C, sheep anti-Myc, and mouse anti-synaptophysin antibodies. In neurons transfected with pClneo Myc PSD-95-4, BEGAIN was not colocalized with synaptophysin (Fig. 8C). As a control, we used pCMV Myc PSD-95-1 encoding the full length of PSD-95. In neurons transfected with pCMV Myc PSD-95-1, BEGAIN was still apposed to the accumulation of synaptophysin in neurons (data not shown). The results are summarized in Table 2.

\section{BEGAIN forms homodimers via the $\mathbf{N}$-terminal region}

As described in Table 1, $60 \%$ of GFP-BEGAIN-2 clusters were colocalized with PSD-95/SAP90, although it did not have a PSD95-interacting region. We consider that GFP-BEGAIN-2 may be targeted with endogenous BEGAIN to synapses. On the basis of this consideration, we examined whether BEGAIN formed multimers. First, we determined the size of GFP-BEGAIN-2 and -4 using the glycerol density gradient. As judged by the values of the sedimentation constants, GFP-BEGAIN-2 behaved as dimers and tetramers, whereas GFP-BEGAIN-4 behaved as monomers

$\leftarrow$

synaptophysin. Scale bar, $5 \mu \mathrm{m}$. $C$, Effect of truncated form of PSD-95/ SAP90 containing the GK domain on synaptic targeting of endogenous BEGAIN. A primary cultured hippocampal neuron was transfected with pClneo Myc PSD-95-4. Seven days after transfection, neurons were immunostained with rabbit anti-BEGAIN-C, sheep anti-Myc, and mouse anti-synaptophysin antibodies and visualized with FITC-conjugated antirabbit, rhodamine-conjugated anti-sheep, and $\mathrm{Cy} 5$-conjugated anti-mouse IgG secondary antibodies. BG, BEGAIN; Myc, Myc-PSD-95-4; Syt, synaptophysin; $B G+S y t$, superimposed image of BEGAIN and synaptophysin. Scale bar, $5 \mu \mathrm{m}$. 


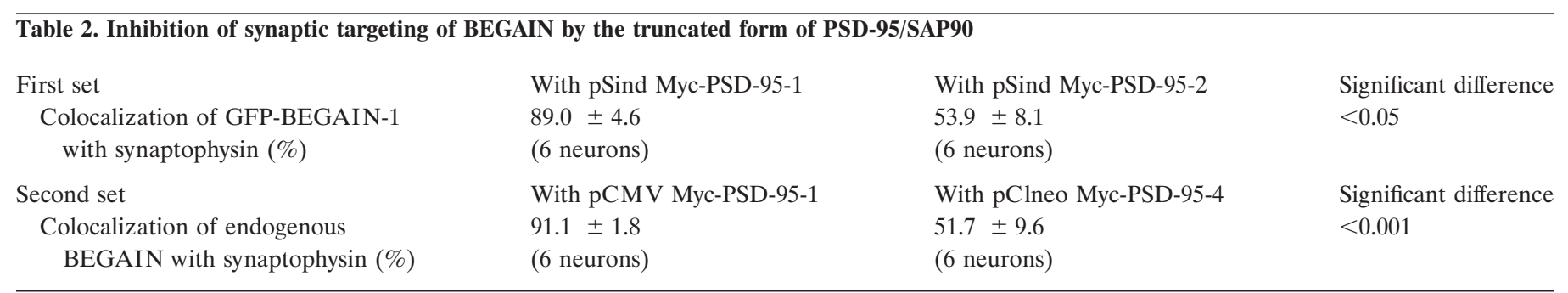

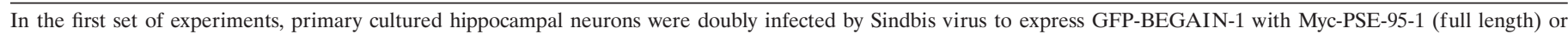

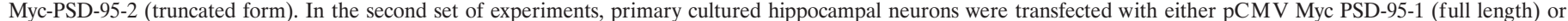

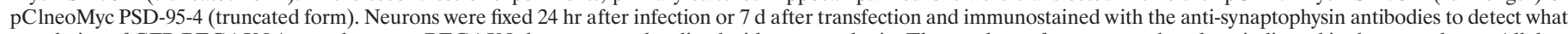

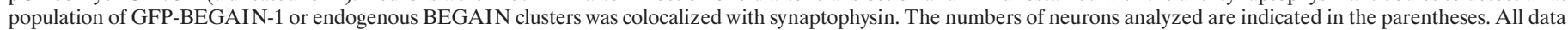
were expressed as mean \pm SEM. The Student's paired $t$ test was used when appropriate to examine the statistical significance of the differences between groups.

(Fig. 9A). The same result was obtained using Myc-BEGAIN-2 (data not shown). In SDS-PAGE gel, GFP-BEGAIN-2 migrated as monomers and dimers. To indicate directly the association of the $\mathrm{N}$-terminal region of BEGAIN with the full length of BEGAIN, we expressed Myc-BEGAIN-1 and -2 in COS cells, immunoprecipitated Myc-BEGAIN-1 with anti-BEGAIN-C antibody, and immunoblotted the precipitates with anti-Myc antibody. MycBEGAIN-2 was coimmunoprecipitated with Myc-BEGAIN-1 (Fig. 9B). These findings support the possibility that GFPBEGAIN-2 interacts with endogenous BEGAIN and is targeted indirectly to synapses.

\section{Recruitment of GFP-BEGAIN-1 to dendrites is independent of NMDA receptor activity, but targeting to synapses depends on NMDA receptor activity}

Extranuclear localization of BEGAIN is observed only in neurons. We tested whether the dendritic and synaptic localization of BEGAIN depends on NMDA receptor activity. First, we treated a hippocampal slice with $100 \mu \mathrm{M}$ DL-2-amino-5-phosphonopentanoic acid (AP-V) (Tocris Cookson). AP-V was added at the same time that the hippocampal slice was infected. GFP-BEGAIN-1 formed clusters at dendrites in AP-V-treated neurons, and the temporal profile of the accumulation at dendrites did not change (Fig. 10 $A$ ). We also tested the NMDA receptor antagonist [5R,10S]-(+)-5methyl-10,11-dihydro-5H-dibenzo[a,d]cyclohepten-5,10-imine, the AMPA receptor antagonist 6-cyano-7-nitroquinoxaline-2,3-dione, the metabotropic glutamate receptor antagonists $[R, S]-\alpha$-cyclopropyl-4-phosphonophenylglycine and [R,S]-1-aminoindan-1,5dicarboxylic acid, and the sodium channel blocker tetrodotoxin. These treatments did not inhibit the accumulation of GFPBEGAIN-1 at dendrites (data not shown). In the experiments using primary cultured hippocampal neurons, we started treatment $6 \mathrm{hr}$ after infection, because expression of the protein was reduced when neurons were treated at the same time with the infection. GFP-BEGAIN-1 was localized at dendrites in AP-Vtreated neurons (Fig. 10Ba); however, GFP-BEGAIN-1 did not colocalize with synaptophysin, suggesting that AP-V inhibited the targeting of BEGAIN to synapses. The treatment with tetrodotoxin showed a similar effect, but treatment with 6-cyano-7nitroquinoxaline-2,3-dione did not affect the synaptic targeting of BEGAIN (Fig. 10Bb,c). The data are summarized in (Table 3 ).

\section{DISCUSSION}

Synapses are highly differentiated submembranous domains for neurotransmission. The study of the molecular organization of synapses is important to understand brain function. Recently, many studies on excitatory synapses with glutamate receptors have been reported. In our current understanding, NMDA and AMPA receptors are associated with multi-PDZ proteins [PSD-95/SAP90,
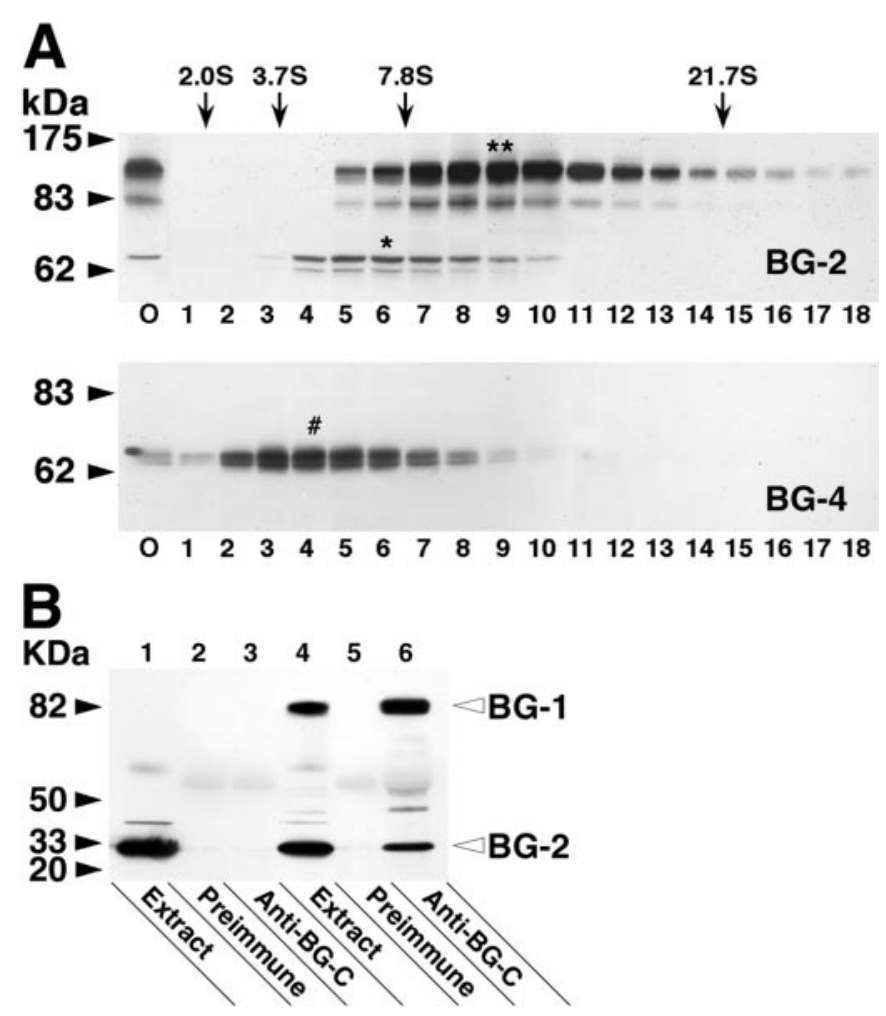

Figure 9. Multimerization of BEGAIN via the N-terminal region. $A$, Multimerization of GFP-BEGAIN-2. Extracts of HeLa cells expressing GFP-BEGAIN-2 or -4 were analyzed on glycerol density gradient, and fractions were immunoblotted with anti-GFP antibody. Numbers at the bottom indicate fraction numbers. The first lanes contain original extracts. Top arrows indicate positions of peaks of marker proteins composed of thyroglobulin $(21.7 \mathrm{~S}, 670 \mathrm{~K})$, bovine $\gamma$-globulin $(7.8 \mathrm{~S}, 158 \mathrm{~K})$, chicken ovalbumin (3.7 S, $44 \mathrm{~K})$, and equine myoglobin (2.0 S, 17.5 K). Top panel, GFP-BEGAIN-2; bottom panel, GFP-BEGAIN-4. GFP-BEGAIN-2 has two peaks. Asterisk indicates the first peak of GFP-BEGAIN-2 that corresponds to dimers in the glycerol density gradient, and the protein migrates as monomers in SDS-PAGE. Double asterisk indicates the second peak as tetramers, and the protein migrates as dimers in SDS-PAGE. GFPBEGAIN-4 is recovered as monomers both in the glycerol density gradient and in SDS-PAGE (\#). B, Coimmunoprecipitation of the N-terminal region of BEGAIN with the full length of BEGAIN. Extracts of COS cells expressing Myc-BEGAIN-2 with or without Myc-BEGAIN-1 were immunoprecipitated with anti-BEGAIN-C antibody that bound only MycBEGAIN-1. Immunoprecipitates were immunoblotted with anti-Myc antibody to see whether Myc-BEGAIN-2 was coimmunoprecipitated. Open arrowheads indicate Myc-BEGAIN-1 and -2. Lanes 1 and 4, Original extracts; lanes 2 and 5, precipitates with preimmune serum; lanes 3 and 6 , precipitates with anti-BEGAIN-C antibody. Lanes 1, 2, and 3, Without Myc-BEGAIN-1; lanes 4, 5, and 6, with Myc-BEGAIN-1. 
Figure 10. Synaptic targeting of GFPBEGAIN blocked by AP-V. A, Temporal profile of expression of GFP-BEGAIN-1 in AP-Vtreated hippocampal slice neurons. Hippocampal slice neurons were infected with Sindbis virus, and $100 \mu \mathrm{M} \mathrm{AP-V}$ was added to the medium simultaneously. GFP-BEGAIN-1 appeared first in nuclei and then formed clusters at dendrites. $a$, Six hours $(6 h)$ after infection; $b, 12 \mathrm{hr}(12 h)$ after infection; $c, 24 \mathrm{hr}(24 \mathrm{~h})$ after infection. Scale bar, $10 \mu \mathrm{m}$. $B$, GFP-BEGAIN-1 in neurons treated with various inhibitors. Primary cultured hippocampal neurons were infected with Sindbis virus to express GFP-BEGAIN-1 and treated with various inhibitors $6 \mathrm{hr}$ after infection. Twenty-four hours later, cells were fixed and immunostained with anti-synaptophysin antibody. Large images are superimposed images of GFP-BEGAIN-1 and synaptophysin. Insets show the demarcated area at higher magnification. $a$, GFP-BEGAIN-1 and synaptophysin in $100 \mu \mathrm{M}$ AP-V-treated neurons. $b$, GFP-BEGAIN-1 and synaptophysin in $1 \mu \mathrm{M}$ tetrodotoxin-treated neurons. $c$, GFP-BEGAIN-1 and synaptophysin in $100 \mu \mathrm{M}$ 6-cyano-7-nitroquinoxaline-2,3-dione-treated neurons. TTX, Tetrodotoxin; $C N Q X$, cyano-7-nitroquinoxaline-2,3dione; $B G$, GFP-BEGAIN-1 (arrows); Syt, synaptophysin (arrowheads); Merge, superimposed image of GFP-BEGAIN-1 and synaptophysin. Scale bar, $10 \mu \mathrm{m}$.
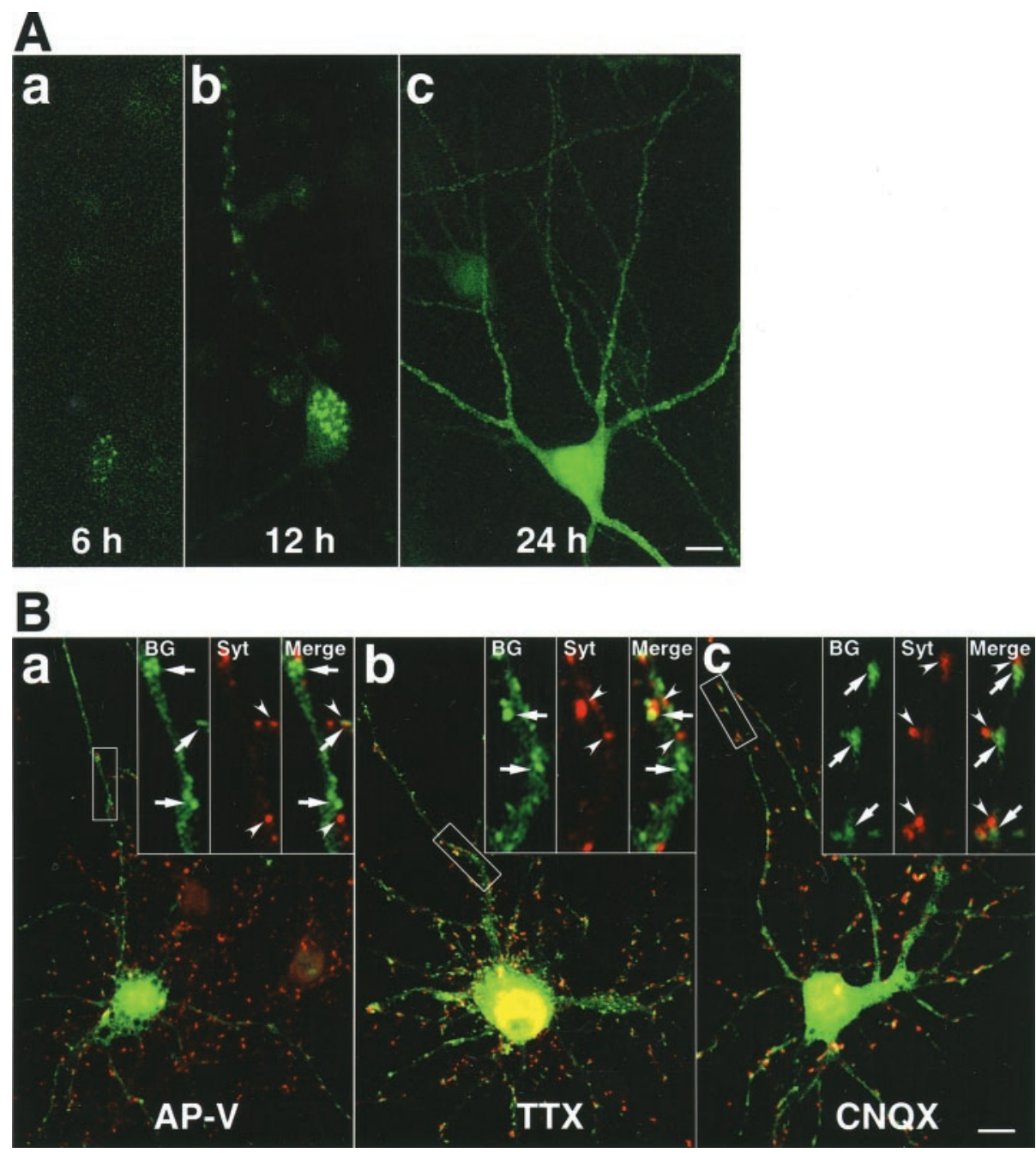

Table 3. Effect of various inhibitors on the synaptic localization of GFP-BEGAIN-1

\begin{tabular}{lllll} 
Type of treatment & Control & AP-V $(100 \mu \mathrm{M})$ & Tetrodotoxin $(1 \mu \mathrm{M})$ & $\begin{array}{l}\text { 6-Cyano-7-nitroquinoxaline- } \\
2,3-\text { dione }(100 \mu \mathrm{M})\end{array}$ \\
\hline Colocalization with synaptophysin $(\%)$ & $73.7 \pm 8.1$ & $51.5 \pm 10.8$ & $56.3 \pm 11.9$ & $71.7 \pm 10.1$ \\
& $(11$ neurons $)$ & $(10$ neurons $)$ & $(8$ neurons $)$ & $(12$ neurons $)$ \\
Significant difference & & $<0.05$ & $<0.05$ & None
\end{tabular}

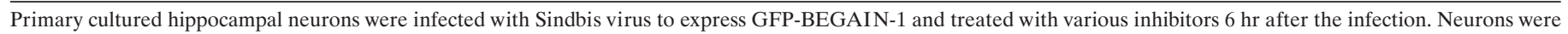

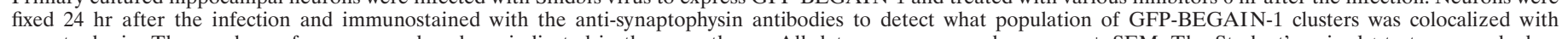

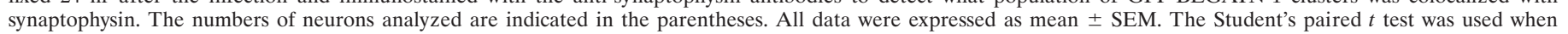
appropriate to examine the statistical significance of the differences between groups.

glutamate receptor-interacting protein/AMPA receptor-binding protein, synaptic scaffolding molecule (S-SCAM)] (Kornau et al., 1995; Dong et al., 1997; Hirao et al., 1998; Srivastava et al., 1998). These PDZ proteins further interact with cell adhesion molecules (neuroligin), cytoskeleton-interacting proteins (GKAP, CRIPT), and molecules of signal transduction (nNOS, synGAP, MAGUIN, RapGEP, fyn, GRASP) (Brenman et al., 1996; Kim et al., 1996, 1998; Irie et al., 1997; Takeuchi et al., 1997; Chen et al., 1998; Niethammer et al., 1998; Ohtsuka et al., 1999; Tezuka et al., 1999; Yao et al., 1999a; Ye et al., 2000). NMDA, AMPA, and metabotropic glutamate receptors are connected through anchoring proteins (Homer/Vesl, Shank/ProSAP/synamon) (Brakeman et al., 1997; Kato et al., 1998; Boeckers et al., 1999; Naisbitt et al., 1999; Yao et al., 1999b). Furthermore, a recent study has revealed that
Stargazin plays an essential role in the synaptic targeting of AMPA receptors through binding to PSD-95/SAP90 (Chen et al., 2000).

We have identified BEGAIN as a protein interacting with the GK domain of PSD-95/SAP90 (Deguchi et al., 1998). BEGAIN does not have any significant homology to known proteins, and the characters of this protein are not yet clear. Here, we report that BEGAIN is localized in nuclei as well as at synapses. In immunohistochemistry and subcellular fractionation, we confirmed the nuclear localization of BEGAIN. The detection of BEGAIN depends on the fixation of samples. In methanol fixation, nuclear BEGAIN is clearly detected, whereas synaptic BEGAIN is remarkable in paraformaldehyde fixation. We have also noticed that anti-BEGAIN-N antibody recognizes nuclear BEGAIN better than anti-BEGAIN-C antibody, and that anti-BEGAIN-C anti- 
body recognizes synaptic BEGAIN better than anti-BEGAIN-N antibody. The reasons for these findings are currently unclear. We speculate as follows: (1) conformation of BEGAIN may be different in nuclei and at synapses; (2) paraformaldehyde may disrupt the antigenicity of the N-terminal region; and (3) synaptic BEGAIN may be lost during methanol fixation. BEGAIN has two nuclear localizing signals in the N-terminal region. The first is PGRLRRA and the second is RRAQEELDKVTEKLRRI (single letters indicate amino acids). Consistently, GFPBEGAIN-2 containing the N-terminal region is localized in nuclei in neurons. Nuclear localization of BEGAIN is also observed, when expressed in non-neuronal cells, and also depends on the N-terminal region. Nuclear localizing signals in the $\mathrm{N}$-terminal region are recognized in both neurons and nonneuronal cells.

Synaptic membrane-associated proteins such as S-SCAM and GKAP are localized at cell-cell contacts when expressed in epithelial cells (W. Nishimura, unpublished observation). These findings suggest that synapses and epithelial junctions have common molecular architectures that are involved in the accumulation of S-SCAM or GKAP at cell-cell contacts. In contrast, BEGAIN shows a different subcellular localization in neurons and epithelial cells. BEGAIN is localized exclusively in nuclei in epithelial cells and is not accumulated at cell-cell contacts, although it is localized at synapses in neurons. We speculate that neurons have a mechanism to recruit BEGAIN from nuclei to dendrites and synapses. We have examined which region of BEGAIN is involved in this process. GFP-BEGAIN-2 containing the $\mathrm{N}$-terminal region of BEGAIN is recruited to dendrites and forms clusters, but not all clusters are at synapses. Because BEGAIN interacts with PSD-95/SAP90 by the C-terminal region, PSD-95/SAP90 may be involved in the synaptic targeting of BEGAIN. We coexpressed GFP-BEGAIN and Myc-tagged PSD-95/SAP90. The full length of PSD-95/SAP90 was accumulated at synapses, and it did not affect the synaptic localization of GFP-BEGAIN. The truncated form of PSD-95/SAP90 lacking the first two PDZ domains was not accumulated at synapses and blocked synaptic targeting of GFP-BEGAIN. Similarly, expression of the truncated form of PSD-95/SAP90 containing the SH3 and GK domains also inhibited synaptic targeting of endogenous BEGAIN. We have also tested whether extranuclear localization of BEGAIN depends on NMDA receptor activity. AP-V treatment disrupts synaptic localization of BEGAIN but does not affect dendritic localization. These findings suggest that recruitment of BEGAIN to synapses is composed of two steps. There may be a neuron-specific component at dendrites that binds the $\mathrm{N}$-terminal region of BEGAIN and recruits BEGAIN from the nucleus, and PSD-95/SAP90 possibly recruits BEGAIN from dendrites to synapses in an NMDA receptor activity-dependent manner.

Several synaptic membrane-associated proteins form homomultimers. PSD-95/SAP90 multimerizes by the N-terminal region (Hsueh et al., 1997). S-SCAM forms dimers by the C-terminal region (Hirao et al., 2000b). Homer/Vesl also forms multimers (Brakeman et al., 1997; Kato et al., 1998). Multimerization may be involved in the clustering of receptors. BEGAIN has a leucine zipper, suggesting that it forms multimers. During this study, we have noticed that the N-terminal region of BEGAIN is partially colocalized with PSD-95/SAP90 in neurons, although it lacks a PSD-95/SAP90-interacting domain. From this observation, we suspect that BEGAIN forms multimers. We have shown using glycerol density gradient and coimmunoprecipitation that BEGAIN actually forms dimers or tetramers by the N-terminal region. BEGAIN may be involved in the clustering of NMDA receptors together with PSD-95/SAP90.

Because we have used BEGAIN2 all through the experiments and we do not have currently the antibody that recognizes BEGAIN1 specifically, we cannot conclude that BEGAIN1 is also localized both in nuclei and at synapses. However, immunofluorescence studies using anti-BEGAIN antibodies and GFP proteins indicate that at least BEGAIN2 shows nuclear and synaptic localization in neurons. The physiological role of nuclear BEGAIN is unclear. Dual localization of BEGAIN implicates that BEGAIN may transfer signals directly between nuclei and synapses. To verify this hypothesis, it is essential to examine what roles BEGAIN plays in nuclei, which molecules recruit BEGAIN from nuclei to dendrites, and whether BEGAIN once targeted to synapses travels back to nuclei.

\section{REFERENCES}

Allison DW, Chervin AS, Gelfand VI, Craig AM (2000) Postsynaptic scaffolds of excitatory and inhibitory synapses in hippocampal neurons: maintenance of core components independent of actin filaments and microtubules. J Neurosci 20:4545-4554.

Boeckers TM, Winter C, Smalla KH, Kreutz MR, Bockmann J, Seidenbecher C, Garner CC, Gundelfinger ED (1999) Proline-rich synapseassociated proteins ProSAP1 and ProSAP2 interact with synaptic proteins of the SAPAP/GKAP family. Biochem Biophys Res Commun 264:247-252.

Brakeman PR, Lanahan AA, O'Brien R, Roche K, Barnes CA, Huganir RL, Worley PF (1997) Homer: a protein that selectively binds metabotropic glutamate receptors. Nature 386:284-288.

Brenman JE, Chao D, Gee SH, McGee AW, Craven SE, Santillano DR Wu Z, Huang F, Xia H, Peters MF, Froehner SC, Bredt DS (1996) Interaction of nitric oxide synthase with the postsynaptic density protein PSD-95/SAP90 and $\alpha 1$-syntrophin mediated by PDZ domains. Cell 84:757-767.

Chen HJ, Rojas-Soto M, Oguni A, Kennedy MB (1998) A synaptic Ras-GTPase activating protein (p135 SynGAP) inhibited by CaM kinase 11. Neuron 20:895-904.

Chen L, Chetkovich DM, Petralia RS, Sweeney NT, Kawasaki Y, Wenthold RJ, Bredt DS, Nicoll RA (2000) Stargazin regulates synaptic targeting of AMPA receptors by two distinct mechanisms. Nature 408:936-943.

Cho KO, Hunt CA, Kennedy MB (1992) The rat brain postsynaptic density fraction contains a homolog of the Drosophila discs-large tumor suppressor protein. Neuron 9:929-942.

Craven SE, El-Husseini AE, Bredt DS (1999) Synaptic targeting of the postsynaptic density protein PSD-95 mediated by lipid and protein motifs. Neuron 22:497-509.

Deguchi M, Hata Y, Takeuchi M, Ide N, Hirao K, Yao I, Irie M, Toyoda A, Takai Y (1998) BEGAIN (brain-enriched guanylate kinaseassociated protein), a novel neuronal PSD-95/SAP90-binding protein. J Biol Chem 273:26269-26272.

Dong H, O'Brien RJ, Fung ET, Lanahan AA, Worley PF, Huganir RL (1997) GRIP: a synaptic PDZ domain-containing protein that interacts with AMPA receptor. Nature 386:279-284.

Goslin K, Asmussen H, Banker G (1998) Rat hippocampal neurons in low-density culture. In: Culturing nerve cells (Banker, G, Goslin K, eds), pp 339-370. Cambridge, MA: MIT.

Hata Y, Takai Y (1999) Roles of postsynaptic density-95/synapseassociated protein 90 and its interacting proteins in the organization of synapses. Cell Mol Life Sci 56:461-472.

Hirao K, Hata Y, Ide N, Takeuchi M, Irie M, Yao I, Deguchi M, Toyoda A, Sudhof TC, Takai Y (1998) A novel multiple PDZ domaincontaining molecule interacting with $N$-methyl-D-aspartate receptors and neuronal cell adhesion protein. J Biol Chem 273:21105-21110.

Hirao K, Hata Y, Deguchi M, Yao I, Ogura M, Rokukawa C, Kawabe H, Mizoguchi A, Takai Y (2000a) Association of synapse-associated protein 90/postsynaptic density-95-associated protein (SAPAP) with neurofilaments. Genes Cell 5:203-210.

Hirao K, Hata Y, Yao I, Deguchi M, Kawabe H, Mizoguchi A, Takai Y (2000b) Three isoforms of synaptic scaffolding molecule and their characterization. J Biol Chem 275:2966-2972.

Hsueh YP, Kim E, Sheng M (1997) Disulfide-linked head-to-head multimerization in the mechanism of ion channel clustering by PSD-95 SAP90. Neuron 18:803-814.

Irie M, Hata Y, Takeuchi M, Ichtchenko K, Toyoda A, Hirao K, Takai Y, Rosahl TW, Sudhof TC (1997) Binding of neuroligins to PSD-95/ SAP90. Science 277:1511-1515. 
Kato A, Ozawa F, Saitoh Y, Fukazawa Y, Sugiyama H, Inokuchi K (1998) Novel members of the Vesl/Homer family of PDZ proteins that bind metabotropic glutamate receptors. J Biol Chem 273:23969-23975.

Kim E, Naisbitt S, Hsueh YP, Rao A, Rothschild A, Craig AM, Sheng M (1996) GKAP, a novel synaptic protein that interacts with the guanylate kinase-like domain of the PSD-95/SAP90 family of channel clustering molecules. J Cell Biol 136:669-678.

Kim JH, Liao D, Lau LF, Huganir RL (1998) SynGAP: a synaptic RasGAP that associates with the PSD-95/SAP90 protein family. Neuron 20:683-691.

Kistner U, Wenzel BM, Veh RW, Cases-Langhoff C, Garner AM, Appeltauer U, Voss B, Gundelfinger ED, Garner CC (1993) SAP90, a rat presynaptic protein related to the product of the Drosophila tumor suppressor gene dlg-A. J Biol Chem 268:4580-4583.

Kornau HC, Schenker LT, Kennedy MB, Seeburg PH (1995) Domain interaction between NMDA receptor subunits and the postsynaptic density protein PSD-95/SAP90. Science 269:1737-1740.

Lee T-H, Kato H, Pan L-H, Ryu JH, Kogure K, Itoyama Y (1998) Localization of nerve growth factor, TrkA and p75 immunoreactivity in the hippocampal formation and basal forebrain of adult rats. Neuroscience 83:335-349.

Naisbitt S, Kim E, Weinberg RJ, Rao A, Yang FC, Craig AC, Sheng M (1997) Characterization of guanylate kinase-associated protein, a postsynaptic density protein at excitatory synapses that interacts directly with postsynaptic density-95/synapse-associated protein 90 . J Neurosci 17:5687-5696.

Naisbitt S, Kim E, Tu JC, Xiao B, Sala C, Valtschanoff J, Weinberg RJ, Worley PF, Sheng M (1999) Shank, a novel family of postsynaptic density proteins that binds to the NMDA receptor/PSD-95/SAP90/ GKAP complex and cortactin. Neuron 23:569-582.

Niethammer M, Valtschanoff JG, Kapoor TM, Allison DW, Weinberg RJ, Craig AM, Sheng M (1998) CRIPT, a novel postsynaptic protein that binds to the third PDZ domain of PSD-95/SAP90. Neuron 20:693-707.

Ohtsuka T, Hata Y, Ide N, Yasuda T, Inoue E, Inoue T, Mizoguchi A,
Takai Y (1999) nRapGEP: a novel neural GDP/GTP exchange protein for Rap1 small $G$ protein that interacts with synaptic scaffolding molecule (S-SCAM). Biochem Biophys Res Commun 265:38-44.

Rickwood D, Messent A, Patel D (1997) Isolation and characterization of nuclei and nuclear subfractions. In: Subcellular fractionation (Graham JM, Rickwood D, eds), pp 71-76. Oxford: IRL.

Satoh K, Yanai H, Send T, Kohu K, Nakamura T, Okumura N, Matsumine A, Kobayashi S, Toyoshima K, Akiyama T (1997) DAP-1, a novel protein that interacts with the guanylate kinase-like domains of hDLG and PSD-95/SAP90. Genes Cell 2:415-424.

Srivastava S, Osten P, Vilim FS, Khatri L, Inman G, States B, Daly C, DeSouza S, Abagyan R, Valtschanoff JG, Weinberg RJ, Ziff EB (1998) Novel anchorage of GluR2/3 to the postsynaptic density by the AMPA receptor-binding protein ABP. Neuron 21:581-591.

Takeuchi M, Hata Y, Hirao K, Toyoda A, Irie M, Takai Y (1997) SAPAPs: a family of PSD-95/SAP90-associated proteins localized at postsynaptic density. J Biol Chem 272:11943-11951.

Tezuka T, Umemori T, Akiyama T, Nakanishi S, Yamamoto T (1999) PSD-95/SAP90 promotes Fyn-mediated tyrosine phosphorylation of the $N$-methyl-D-aspartate receptor subunit NR2A. Proc Natl Acad Sci USA 96:435-440.

Yao I, Hata Y, Ide N, Hirao K, Deguchi M, Nishioka H, Mizoguchi A, Takai Y (1999a) MAGUIN: a novel neuronal membrane-associated guanylate kinase-interacting protein. J Biol Chem 274:11889-11896.

Yao I, Hata Y, Hirao K, Deguchi M, Ide N, Takeuchi M, Takai Y (1999b) Synamon, a novel neuronal protein interacting with synapseassociated protein 90/postsynaptic density-95-associated protein. J Biol Chem 274:27463-27466.

Ye B, Liao D, Zhang X, Zhang P, Dong H, Huganir RL (2000) GRASP-1: a neuronal RasGEF associated with the AMPA receptor/ GRIP complex. Neuron 26:603-617.

Wu G, Lu Z-H, Ledeen RW (1995) Induced and spontaneous neuritogenesis are associated with enhanced expression of ganglioside GM1 in the nuclear membrane. J Neurosci 15:3739-3746. 